\title{
Effect of Solvents and Extraction Methods on Forskolin Content from Coleus forskholii Roots
}

\author{
PRITEE SINGH* AND M. A. SURYANARAYANA ${ }^{1}$ \\ Division of Plant Physiology and Biochemistry, ${ }^{1}$ Division of Ornamental and Medicinal Crops, ICAR- Indian Institute of \\ Horticultural Research, Hessaraghatta Lake Post, Bengaluru-560 089, India
}

Singh et al.: Effect of Solvents and Extraction Methods on Forskolin

\begin{abstract}
Coleus forskohlii roots are mainly used for extraction of the bioactive diterpenoid, forskolin, which has enormous biological activities. In this study, impact of the solvent and extraction method on forskolin content from Coleus forskohlii root powder was investigated. Nine solvents from different polarity group were tested for forskolin extraction. It was found that the efficiency of the solvents used to extract forskolin varied considerably ( 0.18 to $2.91 \%)$. The average values indicated that among all the extractives, forskolin content was significantly higher in methanol (2.91\%), followed by ethanol $(2.59 \%)$, and least content was found in water $(0.18 \%)$. Low polarity solvents were not found very effective for forskolin extraction. Further three different extraction methods (Soxhlet/refluxing, ultrasound and microwaveassisted solvent extraction) were also compared using safest and most effective solvent for forskolin yield. As ethanol exhibited good extraction efficiency for forskolin and is a safe solvent, it was chosen for further optimization of extraction method. Soxhlet extraction technique gave higher yield of forskolin $(0.17$ to $2.83 \%)$ compared to microwave-assisted solvent extraction $(0.09$ to $2.29 \%)$ and ultra sound-assisted extraction ( $(0.08$ to $1.47 \%)$. From these results it was evident that the extraction of forskolin depended on extraction process as well as the solvent useds.
\end{abstract}

Key words: Coleus forskohlii, extraction method, extraction solvent, forskolin

Coleus forskohlii is an important medicinal plant grown in the tropical and subtropical regions of Asia and Africa including India and is well known for its medicinal uses ${ }^{[1]}$. The tuberous roots of C. forskohlii produce forskolin (diterpenoid, fig. 1), which has been used in traditional as well as modern medicines. In the 


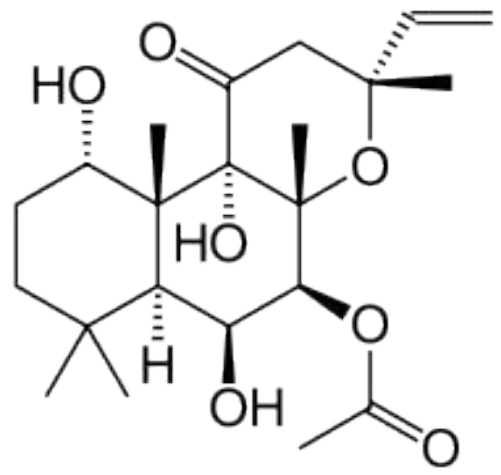

Fig. 1: Structure of forskolin

traditional system of medicine, stem and roots are being used as analgesic, antiinflammatory, antihemorrhoidal and anthelmintic agent. Apart from this, it is also helpful in treatment of hypertension, glaucoma, piles, inflammation, cough, tumour, skin diseases, ascites, gastric problems, spleen diseases, constipation, anorexia and anuria ${ }^{[2,3]}$. Currently medicinal plants are sought for development of safe drugs ${ }^{[4]}$. Phytoconstituent present in these plants are essential in generation of different drugs. These phytoconstituents vary in physical and chemical characteristics ${ }^{[5]}$ and their recovery depends on extraction technique and the nature of solvent ${ }^{[6,7]}$.

Forskolin occurrence in plants is reported to be in low concentration and extraction method and solvent are the important factors, which influence the extraction efficiency of medicinally important compounds from plant material. Hence it is necessary to choose a requisite extraction solvent and extraction method for complete extraction of this bioactive compound present in Coleus.

To our knowledge, best method and solvent for extraction of forskolin have not yet been reported. The objectives of this work were (i) to study the effect of solvent on extraction of the $C$. forskohlii diterpenoid forskolin, and to determine the best solvent for its extraction and (ii) to study the effect of different methods for the extraction of forskolin from C. forskohlii. Standard Soxhlet extraction with different solvents was used in order to determine the best solvent for extraction of forskolin from $C$. forskohlii. Further, to standardise the best extraction method, safe and most effective solvent was used with different extraction methods. This work would help to standardize the best solvent and extraction method for quantification of forskolin content in different genotypes, which would help in screening of Coleus genotypes for higher forskolin. This information would also aid in developing efficient extraction and analysis procedure, which would also help pharmaceutical industries.

High performance liquid chromatography (HPLC) grade acetone, chloroform, di-chloromethane, ethyl acetate, ethanol, hexane, methanol, petroleum ether and acetonitrile were purchased from Merck India. Certified reference standard of forskolin obtained from Sigma-Aldrich, USA and stored at $-20^{\circ}$.

Dried root powder of $C$. forskohlii was provided by Division of Floriculture and Medicinal Crops, ICARIndian Institute of Horticultural Research (IIHR), Hessaraghatta, Bengaluru, India. To compare different solvents, 9 pure solvents representing different polarity groups like non-polar group (hexane and petroleum ether), intermediate polarity group (ethyl acetate, di-chloromethane and chloroform) and polar group (acetone, ethanol, methanol and water) were used in extraction process. Five grams of Coleus root powder was extracted for $5 \mathrm{~h}$ in a Soxhlet using $150 \mathrm{ml}$ of each solvent.

To evaluate different extraction methods, 3 safe solvents were used, water, water-ethanol (9:1) mixture and pure ethanol with Soxhlet, microwave and ultrasonication methods of extraction. For Soxhlet, $5 \mathrm{~g}$ of root powder was extracted with $150 \mathrm{ml}$ solvent for $5 \mathrm{~h}$ using these safe solvents. For microwave-assisted solvent extraction (MASE), $5 \mathrm{~g}$ of sample was mixed with $50 \mathrm{ml}$ of all the 3 solvents separately in beakers. Beakers were placed in the middle of the rotating plate of a microwave oven (LG Electronics, India, modelIntello wave) and extracted for 5, 10 and $20 \mathrm{~min}$. Ultrasound assisted extraction (UASE) was carried out using a sonicator at $20 \mathrm{kHz}$ (Sonics Vibra cell, model: $\mathrm{VC} 505, \mathrm{~S} / \mathrm{N}:$ 61588AC-02-11). About $5 \mathrm{~g}$ of ground powder was mixed with $50 \mathrm{ml}$ of distilled water, ethanol and water-ethanol (9:1) separately in beakers and extraction was carried out for 5, 10 and $20 \mathrm{~min}$. All the extraction experiments were performed thrice. To separate the liquid extract in the above extraction

This is an open access article distributed under the terms of the Creative Commons Attribution-NonCommercial-ShareAlike 3.0 License, which allows others to remix, tweak, and build upon the work non-commercially, as long as the author is credited and the new creations are licensed under the identical terms

Accepted 25 September 2019

Revised 24 June 2019

Received 15 April 2019 Indian J Pharm Sci 2019;81(6):1136-1140 
methods, they were filtered and concentrated using a rotary evaporator. For the analysis the dried extracts were dissolved in $50 \mathrm{ml}$ methanol and filtered through 0.45 microns membrane filter paper for HPLC analysis.

Quantitative estimation of forskolin content was performed as per the method described in literature ${ }^{[8]}$ using a Shimadzu Nexera X2 ultra high-performance liquid chromatograph with PDA detector adjusted to $220 \mathrm{~nm}$. Stainless steel column $(250 \times 4.6 \mathrm{~mm})$ packed with octadecylsilane bonded to porous silica $(5 \mu)$ and acetonitrile-distilled water (45:55) was used as mobile phase. Flow rate was adjusted to $1.5 \mathrm{ml} / \mathrm{min}$ and sample volume of $20 \mu \mathrm{l}$ was injected. Retention time of forskolin and total run time was $15.93 \mathrm{~min}$ (fig. 2) and $25 \mathrm{~min}$, respectively.

Data was analysed using the Statistical Analysis System software (SAS version 9.3) to determine the effects of solvent and extraction method on forskolin content. The results were statistically analysed by ANOVA and means were compared using Tukey's test. The level of statistical significance was set at $\mathrm{p} \leq 0.05$.

Most of the biologically active compounds occurring in plants have been used for commercial application in the manufacture of drugs, flavours and pesticides because of presence of antioxidant, antibacterial, antihypertensive and antiinflammatory properties ${ }^{[9]}$. But occurrences of these bioactive compounds in plants are meagre. Therefore, it is necessary to select suitable extraction solvent as well as extraction method to obtain maximum extraction efficiency of a particular compound. Extraction efficiency of bioactive compounds is influenced by the chemical nature of the compound, method of extraction and the solvents used for extraction ${ }^{[10]}$. Apart from this, the yield of extract also depends on solvent polarity, $\mathrm{pH}$, temperature and extraction time ${ }^{[11]}$. Therefore, the present study was carried out to see the effect of solvents and methods of extraction on forskolin content in C. forskholii.

Data pertaining to forskolin content obtained from different solvent extracts are presented in Table 1. The results indicated that highest forskolin content was obtained from methanol $(2.91 \%)$ and ethanol $(2.59 \%)$, which are polar in nature while minimum forskolin content was observed in water $(0.18 \%)$, since most terpenoid are hydrophobic and difficult to dissolve in water ${ }^{[12]}$. It is well known that high polarity, low viscosity, surface tension and vapor pressure will play a key role in increasing the terpenoid yield ${ }^{[13]}$ and because of these properties methanol gave the highest yield of forskolin. Solvents with lower polarity such as n-hexane $(0.93 \%)$ and petroleum ether $(0.28 \%)$, and intermediate polarity solvents such as ethyl acetate $(1.60 \%)$, dichloromethane $(0.41 \%)$ and chloroform $(0.33 \%)$ were not found to be very effective in extracting forskolin (Table 1). Cell wall permeability and contact between the solvent and solid is improved by polar solvents which increased the extraction yield ${ }^{[14]}$. These results agree with the work reported by Kumoro et al. ${ }^{[15]}$. They also found methanol followed by ethanol as best solvent for extraction of andrographolide (a diterpenoid) from Andrographis paniculata. In the past similar

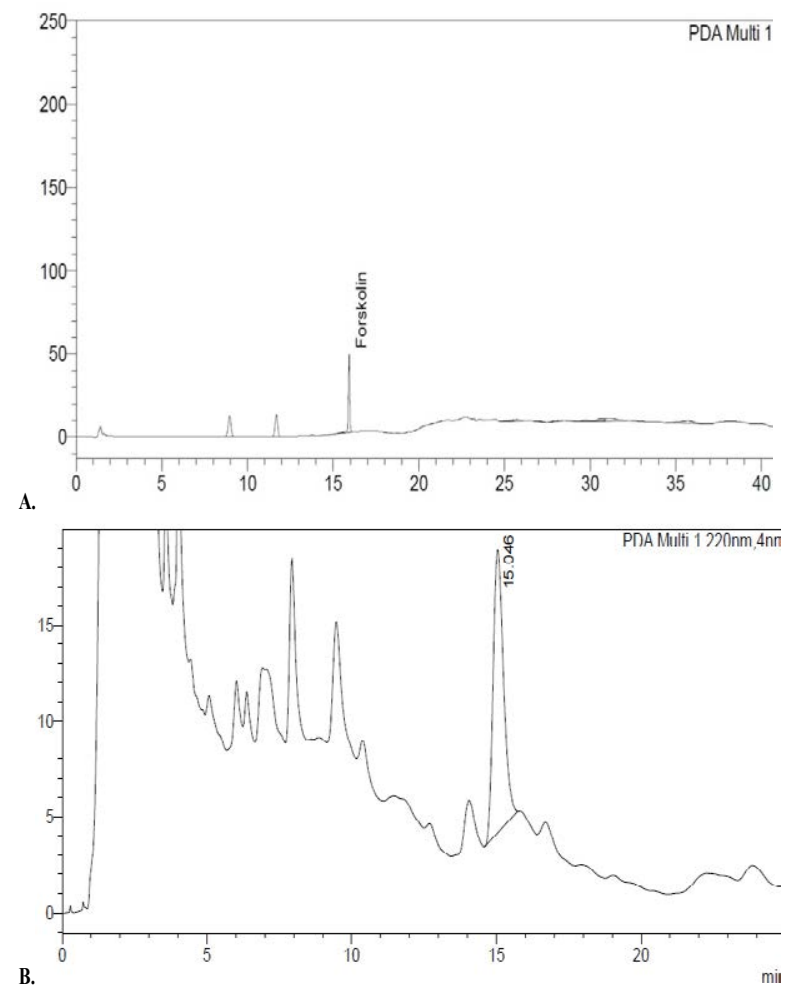

Fig. 2: HPLC chromatograms of forskolin and forskolin in Coleus root extract

HPLC chromatogram of (A) standard forskolin at RT $15.93 \mathrm{~min}$ and (B) chromatogram of forskolin in Coleus root extract

TABLE 1: EFFECT OF SOLVENT PROPERTIES ON YIELD OF FORSKOLIN

\begin{tabular}{lccc}
\hline Solvent & $\begin{array}{c}\text { Polarity } \\
\text { index }\end{array}$ & $\begin{array}{c}\text { Boiling } \\
\text { point }\left({ }^{\circ}\right)\end{array}$ & $\begin{array}{c}\text { Forskolin content } \\
\text { (g/100 g dried } \\
\text { roots) }\end{array}$ \\
\hline Chloroform & 4.1 & 61 & $0.33 \pm 0.055^{\mathrm{fg}}$ \\
Di-chloromethane & 3.1 & 41 & $0.41 \pm 0.036^{\mathrm{ef}}$ \\
Hexane & 0.0 & 69 & $0.93 \pm 0.040^{\mathrm{d}}$ \\
Petroleum ether & 0.0 & $42-62$ & $0.28 \pm 0.007^{\mathrm{fg}}$ \\
Acetone & 5.1 & 56 & $0.50 \pm 0.106^{\mathrm{e}}$ \\
Ethyl acetate & 4.4 & 77 & $1.60 \pm 0.092^{\mathrm{c}}$ \\
Ethanol & 5.2 & 78 & $2.59 \pm 0.108^{\mathrm{b}}$ \\
Methanol & 5.1 & 65 & $2.91 \pm 0.026^{\mathrm{a}}$ \\
Water & 9.0 & 100 & $0.18 \pm 0.029 \mathrm{~g}$ \\
\hline
\end{tabular}

Forskolin content represent the mean of three replicates (mean \pm SD, $n=3$ ). Means with the same superscripts are not significantly different $(p<0.05)$ 
studies have been reported, in which extractability of acetone, methanol, ethanol and water for extracting antioxidants and phenolic compounds ${ }^{[16,17]}$, methanol, ethanol, ethyl acetate, water, and acetone for extracting polyphenols and antimicrobial compounds ${ }^{[18]}$, water, methanol, ethanol, acetone, ethyl acetate and acidic methanol for extracting antioxidants and phenolic compounds were compared ${ }^{[19]}$.

The data regarding forskolin content extracted using Soxhlet/refluxing, MASE and UASE are summarized in Table 2. Among these methods the maximum forskolin content was extracted by Soxhlet extraction (2.83 \%). In many other cases as well, Soxhlet extraction was found most effective for extraction of terpenoids and sterols from tobacco ${ }^{[20]}$, and cucurbitacin from wild bottle gourd ${ }^{[21]}$. This might be due to thermal degradation and oxidation of most of the bioactive compounds in MASE, which might not happen in Soxhlet extraction ${ }^{[22-24]}$. While in case of UASE use of ultrasound energy at higher frequencies $(>20 \mathrm{kHz})$ have a negative impact on bioactive compounds because of formation of free radicals ${ }^{[25,20]}$. Though there were many

TABLE 2: EFFECT OF DIFFERENT EXTRACTION METHODS ON YIELD OF FORSKOLIN

\begin{tabular}{|c|c|c|}
\hline $\begin{array}{l}\text { Extraction } \\
\text { method }\end{array}$ & Treatment & $\begin{array}{c}\text { Forskolin content } \\
\text { (g/100 g dried } \\
\text { roots) }\end{array}$ \\
\hline \multirow{6}{*}{$\begin{array}{l}\text { Reflux } \\
\text { (Soxhlet) }\end{array}$} & Water, $5 \mathrm{~h}$ & $0.17 \pm 0.015^{\text {gh }}$ \\
\hline & Water-ethanol (9:1), $5 \mathrm{~h}$ & $0.26 \pm 0.02^{f}$ \\
\hline & Ethanol, $5 \mathrm{~h}$ & $2.83 \pm 0.101^{\mathrm{a}}$ \\
\hline & Water, 5 min & $0.09 \pm 0.005^{j}$ \\
\hline & Water, $10 \mathrm{~min}$ & $0.13 \pm 0.008^{\text {ghi }}$ \\
\hline & Water, $20 \mathrm{~min}$ & $0.13 \pm 0.002^{\text {ghi }}$ \\
\hline \multirow{8}{*}{ MASE } & $\begin{array}{l}\text { Water-ethanol }(9: 1), 5 \\
\min \end{array}$ & $0.16 \pm 0.005^{\text {gh }}$ \\
\hline & $\begin{array}{l}\text { Water-ethanol }(9: 1), 10 \\
\min \end{array}$ & $0.18 \pm 0.007^{\mathrm{g}}$ \\
\hline & $\begin{array}{l}\text { Water-ethanol }(9: 1), 20 \\
\min \end{array}$ & $0.31 \pm 0.008^{e}$ \\
\hline & Ethanol, $5 \mathrm{~min}$ & $2.29 \pm 0.063^{b}$ \\
\hline & Water, 5 min & $0.08 \pm 0.006^{j}$ \\
\hline & Water, $10 \mathrm{~min}$ & $0.09 \pm 0.005^{j}$ \\
\hline & Water, $20 \mathrm{~min}$ & $0.09 \pm 0.003^{j}$ \\
\hline & $\begin{array}{l}\text { Water-ethanol (9:1), } 5 \\
\min \end{array}$ & $0.10 \pm 0.005^{i j}$ \\
\hline \multirow[t]{5}{*}{ UASE } & $\begin{array}{l}\text { Water-ethanol }(9: 1), 10 \\
\min \end{array}$ & $0.13 \pm 0.006 h^{\text {ghi }}$ \\
\hline & $\begin{array}{l}\text { Water-ethanol }(9: 1), 20 \\
\min \end{array}$ & $0.15 \pm 0.003^{\mathrm{gh}}$ \\
\hline & Ethanol, $5 \mathrm{~min}$ & $1.02 \pm 0.014^{d}$ \\
\hline & Ethanol, $10 \mathrm{~min}$ & $1.04 \pm 0.010^{d}$ \\
\hline & Ethanol, $20 \mathrm{~min}$ & $1.47 \pm 0.030^{c}$ \\
\hline
\end{tabular}

Forskolin content is the mean of three replicates (mean $\pm S D, n=3$ ). Means with the same superscripts are not significantly different $(\mathrm{p}<0.05)$

November-December 2019 studies that reported $\mathrm{MASE}^{[26,27]}$ and $\mathrm{UASE}^{[28,29]}$ to be most effective for isolation of bioactive compounds, which could be that the effectiveness of extraction depended on the nature of compound and plant species.

In the Soxhlet extraction method, maximum forskolin content was found in the ethanol extract $(2.83 \%)$ followed by water-ethanol extract $(0.26 \%)$. Minimum forskolin content was found in water extract $(0.17 \%)$. For MASE and UASE methods extraction times of 5, 10 and 20 min were used. Using the MASE method, ethanol extracted maximum forskolin content $(2.29 \%, 5 \mathrm{~min})$ followed by water-ethanol $(0.31 \%$, $20 \mathrm{~min}$ ) while, the minimum forskolin content was extracted by water $(0.09 \%, 5 \mathrm{~min})$. In case of the UASE method, it was found that the yield increased with increasing the time of exposure to sonication. The ethanol extract yielded maximum forskolin $(1.47 \%$, $20 \mathrm{~min}$ ), while the water extract yielded the minimum $(0.08 \%, 5 \mathrm{~min})$. In all the three extraction methods ethanol extracted maximum forskolin compared to the other extracts. The reason behind this could be insolubility of forskolin in water even though the polarity of water is high. Also this might be due to extraction efficiency of solvents which depended on solubility of compound in the solvents ${ }^{[29]}$.

To conclude, polar solvents like methanol followed by ethanol extracted highest forskolin content in all the extraction methods employed and Soxhlet extraction method was found to be the best. The findings of this study could prove to be important for practical pharmacy for better extraction of forskolin.

\section{Acknowledgements:}

The authors wish to thank the Director, ICAR-IIHR, Bengaluru for providing the facilities for conducting the study.

\section{Conflict of interest:}

Authors have declared that they have no conflict of interest.

\section{REFERENCES}

1. Kavitha C, Rajaman K, Vadivel E. Coleus forskholii: A comprehensive review on morphology, phytochemistry and pharmacological aspects. J Med Plants Res 2010;4(4):278-85.

2. Fale PLV, Ascensao L, Serralheiro ML, Haris PI. Interaction between Plectranthus barbatus herbal tea components and acetylcholinesterase: binding and activity studies. Food Funct 2012;3(11):1176-84.

3. DeSouza NJ, Dohodwalla AN, Rupp RM. Forskolin - Its chemical, biological and medicinal potential. Mumbai, India: Hoechst India Ltd.; 1986. p. 77. 
4. Senapati MR, Behera PC, Bisoi PC, Maity A, Parija SC. HPTLC finger print analysis of phytophenols of Paederia foetida under different extraction regimen. Bioscan 2013;8(2):603-9.

5. Sultana B, Anwar F, Ashraf M. Effect of extraction solvent/ technique on the antioxidant activity of the selected medicinal plant extracts. Molecules 2009;14(6):2167-80.

6. Turkmen N, Sari F, Velioglu YS. Effects of extraction solvents on concentration and antioxidant activity of black and black mate tea polyphenols determined by ferrous tartrate and FolinCiocalteu methods. Food Chem 2006;99(4):835-91.

7. Truong DH, Nguyen DH, Ta NTA, Bui AV, Do TH, Nguyen HC. Evaluation of the Use of Different Solvents for Phytochemical Constituents, Antioxidants, and In Vitro AntiInflammatory Activities of Severinia buxifolia. J Food Qual 2019;2019:8178294.

8. Nidiry ESJ, Ganeshan G, Lokesha AN. Antifungal activity of the extractives of Coleus forskohlii roots and Forskolin. Pharm Chem J 2015;49(9):624-6.

9. Zlotek U, Mikulska S, Nagajek M, Swieca, M. The effect of different solvents and number of extraction steps on the polyphenol content and antioxidant capacity of basil leaves (Ocimum basilicum L.) extracts. Saudi J Biol Sci 2016;23(5):628-33.

10. Casagrande M, Zanela J, Júnior AW, Busso C, Wouk J, Iurckevicz $\mathrm{G}$, et al. Influence of time, temperature and solvent on the extraction of bioactive compounds of Baccharis dracunculifolia: In vitro antioxidant activity, antimicrobial potential, and phenolic compound quantification. Ind Crops Prod 2018;125:207-19.

11. Stalikas CD. Extraction, separation and detection methods for phenolic acids and flavonoids. J Sep Sci 2007;30(18):3268-95.

12. Liu WJH. Traditional Herbal Medicine Research Methods: Identification, Analysis, Bioassay, and Pharmaceutical and Clinical Studies. Hoboken, New Jersey, United States: Willey; 2011. p. 488.

13. Rao PR, Rathod VK. Mapping study of an ultrasonic bath for the extraction of andrographolide from Andrographis paniculata using ultrasound. Ind Crops Prod 2015;66:312-8.

14. Jadhav D, Rekha BN, Gogate PR, Rathod VK. Extraction of vanillin from vanilla pods: a comparison study of conventional soxhlet and ultrasound assisted extraction. J Food Eng 2009;93(4):421-6.

15. Kumoro AC, Hasan M, Singh H. Effects of solvent properties on the Soxhlet extraction of diterpenoid lactones from Andrographis paniculata leaves. Sci Asia 2009;35:306-9.

16. El-Chaghaby GA, Ahmad AF, Ramis ES. Evaluation of the antioxidant and antibacterial properties of various solvents extracts of Annona squamosa L. leaves. Arab J Chem 2014; 7:227-33.

17. Li H, Zhang D, Tan LH, Yu B, Zhao SP, Cao WG. Comparison of the antioxidant properties of various solvent extracts from
Dipsacus asperoides and identification of phenolic compounds by LC-ESI-QTOF-MS-MS. S Afric J Bot 2017;109:1-8.

18. Prabakaran M, Kim SH, Sasireka A, Chandrasekaran M, Chung IM. Polyphenol composition and antimicrobial activity of various solvent extracts from different plant parts of Moringa oleifera. Food Biosci 2018;26:23-9.

19. Ismail BB, Pu Y, Guo M, Ma X, Liu D. LC-MS/QTOF identification of phytochemicals and the effects of solvents on phenolic constituents and antioxidant activity of baobab (Adansonia digitata) fruit pulp. Food Chem 2019;277:279-88.

20. Shen J, Shao X. A comparison of accelerated solvent extraction, Soxhlet extraction, and ultrasonic-assisted extraction for analysis of terpenoids and sterols in tobacco. Anal Bioanal Chem 2005;383(6):1003-8.

21. Attar UA, Ghane SG. Optimized extraction of anti-cancer compound - cucurbitacin I and LC-MS identification of major metabolites from wild Bottle gourd (Lagenaria siceraria (Molina) Standl.). S Afr J Bot 2018;119:181-7.

22. Kaufmann B, Christen P. Recent extraction techniques for natural products: Microwave-assisted extraction and pressurised solvent extraction. Phytochem Anal 2002;13(2):105-13.

23. Trusheva B, Trunkova D, Bankova V. Different extraction methods of biologically active components from propolis: a preliminary study. Chem Cent 2007;1:13.

24. Anuradha M, Pragyandip PD, Richa K, Murthy PN. Evaluation of Neuropharmacological Effects of Ethanolic Extract of Clitorea Ternatea Flowers. Pharmacol Online 2010;1:284-92.

25. Handa SS, Khanuja SPS, Longo G, Rakesh DD. Extraction Technologies for Medicinal and Aromatic Plants. 1st ed. Trieste, Italy: United Nations Industrial Development Organization and the International Centre for Science and High Technology; 2008. p. 60.

26. Milenaa V, Tatjanab M, Gökhanc Z, Ivanab B, Aleksandraa C, Mohammadd MF, et al. Advantages of contemporary extraction techniques for the extraction of bioactive constituents from black elderberry (Sambucus nigra L.) flowers. Ind Crops Prod 2019;136:93-101.

27. Nayak B, Dahmoune F, Moussi K, Remini H, Dairi S, Aoun O, et al. Comparison of microwave, ultrasound and acceleratedassisted solvent extraction for recovery of polyphenols from Citrus sinensis peels. Food Chem 2015;187:507-16.

28. Backesa E, Pereira C, Barros L, Prieto MA, Genenad AK, Barreiroa MF, et al. Recovery of bioactive anthocyanin pigments from Ficus carica L. peel by heat, microwave, and ultrasound based extraction techniques. Food Res Int 2018;113:197-209.

29. Dhanani T, Shah S, Gajbhiye NA, Kumar S. Effect of extraction methods on yield, phytochemical constituents and antioxidant activity of Withania somnifera. Arab J Chem 2013;10Suppl $1:$ S1193-9. 